\section{BMJ Open Respiratory Research}

\title{
Chest drain aerosol generation in COVID-19 and emission reduction using a simple anti-viral filter
}

Clodagh Duffy, ${ }^{1}$ Andrew Kidd, ${ }^{2,3}$ Sarah Francis, ${ }^{1}$ Selina Tsim, ${ }^{2,3}$ Laura McNaughton, ${ }^{2}$ Katie Ferguson,, ${ }^{2,3}$ Jenny Ferguson, ${ }^{2,3} \mathrm{~K}$ Gary Rodgers, ${ }^{4}$ Claire McGroarty, ${ }^{4}$ Robin Sayer, ${ }^{1}$ Kevin G Blyth (D) ${ }^{3,5}$

\section{ABSTRACT}

To cite: Duffy C, Kidd A, Francis S, et al. Chest drain aerosol generation in COVID-19 and emission reduction using a simple anti-viral filter. BMJ Open Resp Res 2020;7:e000710. doi:10.1136/ bmjresp-2020-000710

- Additional material is published online only. To view, please visit the journal online (http://dx.doi.org/10. 1136/bmjresp-2020-000710).

$\mathrm{CD}$ and $\mathrm{AK}$ contributed equally.

Received 11 July 2020 Revised 27 August 2020 Accepted 7 October 2020

Check for updates

\section{(c) Author(s) (or their} employer(s)) 2020. Re-use permitted under CC BY-NC. No commercial re-use. See rights and permissions. Published by BMJ.

${ }^{1}$ Medical Devices Unit, NHS Greater Glasgow and Clyde, Glasgow, UK

${ }^{2}$ Respiratory Medicine, Queen Elizabeth University Hospital, Glasgow, UK

${ }^{3}$ Institute of Cancer Sciences, University of Glasgow, Glasgow, UK

${ }^{4}$ Emergency Department, Queen Elizabeth University Hospital, Glasgow, UK ${ }^{5}$ Glasgow Pleural Disease Unit, Respiratory Medicine, Queen Elizabeth University Hospital, Glasgow, UK

Correspondence to Dr Kevin G Blyth; kevin.blyth@glasgow.ac.uk area. SARS-CoV-2.
Introduction The COVID-19 pandemic has been

characterised by significant in-hospital virus transmission and deaths among healthcare workers. Sources of inhospital transmission are not fully understood, with special precautions currently reserved for procedures previously shown to generate aerosols (particles $<5 \mu \mathrm{m}$ ). Pleural procedures are not currently considered AGPs (Aerosol Generating Procedures), reflecting a lack of data in this

Methods An underwater seal chest drain bottle (R54500, Rocket Medical UK) was set up inside a 60-litre plastic box and connected via an airtight conduit to a medical air supply. A multichannel particle counter (TSI Aerotrak 9310 Aerosol Monitor) was placed inside the box, allowing measurement of particle count/cubic foot $\left(\mathrm{pc} / \mathrm{ft}^{3}\right)$ within six channel sizes: $0.3-0.5,0.5-1,1-3,3-5,5-10$ and $>10 \mu \mathrm{m}$. Stabilised particle counts at 1,3 and $5 \mathrm{~L} / \mathrm{min}$ were compared by Wilcoxon signed rank test; $p$ values were Bonferroni-adjusted. Measurements were repeated with a simple anti-viral filter, designed using repurposed materials by the study team, attached to the drain bottle. The pressure within the bottle was measured to assess any effect of the filter on bottle function.

Results Aerosol emissions increased with increasing air flow, with the largest increase observed in smaller particles $(0.3-3 \mu \mathrm{m})$. Concentration of the smallest particles $(0.3-$ $0.5 \mu \mathrm{m})$ increased from background levels by 700,1400 and $2500 \mathrm{pc} / \mathrm{ft}^{3}$ at 1,3 and $5 \mathrm{~L} / \mathrm{min}$, respectively. However, dispersion of particles of all sizes was effectively prevented by use of the viral filter at all flow rates. Use of the filter was associated with a maximum pressure rise of $0.3 \mathrm{~cm}$ $\mathrm{H}_{2} \mathrm{O}$ after 24 hours of flow at $5 \mathrm{~L} / \mathrm{min}$, suggesting minimal impact on drain function.

Conclusion A bubbling chest drain is a source of aerosolised particles, but emission can be prevented using a simple anti-viral filter. These data should be considered when designing measures to reduce in-hospital spread of

\section{INTRODUCTION}

Previous coronavirus epidemics were characterised by high infection rates in healthcare workers (HCWs) and 'super-spreading' events within hospitals. Despite implementation of WHO guidance designed to reduce

\section{Key messages}

- The objectives of this study were to determine whether a bubbling chest drain is aerosol-generating and the efficacy of a simple anti-viral filter.

- A bubbling chest drain is a source of aerosolised particles, but emission can be prevented using a simple anti-viral filter.

- The WHO and expert groups, including the British Thoracic Society, disagree on the risks posed by pleural procedures during the COVID-19 pandemic. This reflects the absence of any prior data on whether pleural procedures generate aerosols and merit risk mitigation. This study is the first to examine this question.

in-hospital spread, ${ }^{1}$ nosocomial and HCW infection have remained prominent features of the current COVID-19 pandemic, with $43.5 \%$ of UK HCWs becoming seropositive over a 1-month period in one recent study. ${ }^{2}$ Better understanding of in-hospital infection sources is therefore urgently needed. Pleural procedures are not currently considered aerosol-generating by the $\mathrm{WHO},{ }^{1}$ and special precautions to mitigate against viral transmission and/or to protect HCWs are not currently recommended. However, this is based on the absence of any prior data regarding the aerosol-generating potential of a chest drain (where an aerosol is defined as a particle smaller than $5 \mu \mathrm{m}$ ) rather than a robust understanding of the level of risk involved. Recent studies report detection of SARS-CoV-2 in COVID-19-associated pleural effusion ${ }^{34}$ and 'super-spreading' events linked to chest drain use. The latter includes a cohort of 25 Chinese patients (including $12 \mathrm{HCWs}$ ) infected from a single index case who underwent elective lobectomy with undetected SARS-CoV-2 infection. ${ }^{5}$ This has prompted expert bodies, including the British Thoracic Society (BTS) ${ }^{6}$ and the American Association 
A

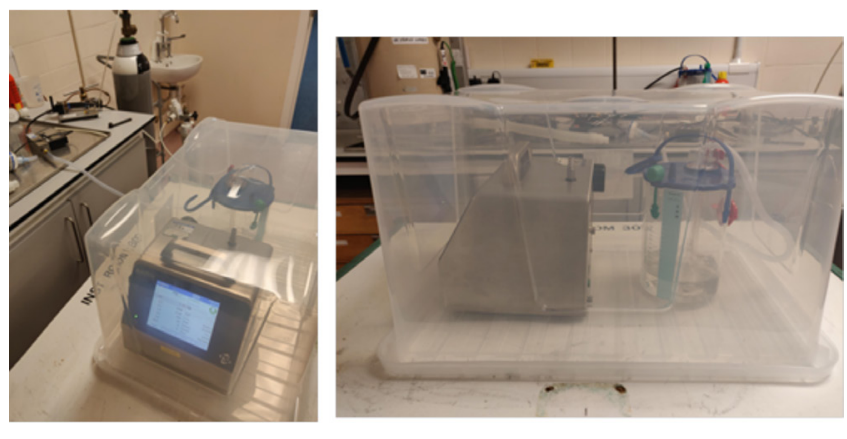

B

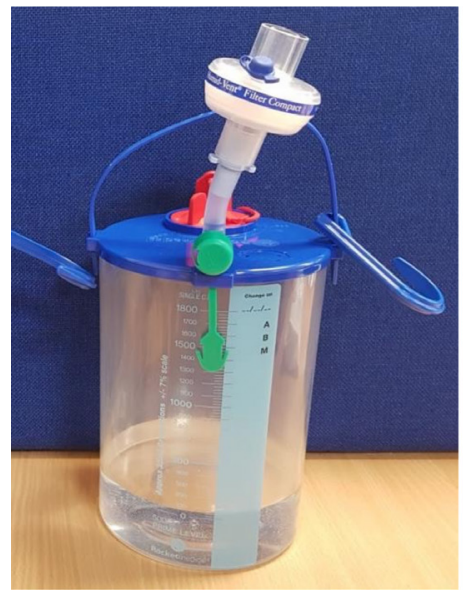

Figure 1 (A) Experimental set-up including the Aerotrak 9310 (to the left of the images) and the underwater seal chest drain bottle (Rocket R54500, to the right of the images) inside the sealed 60-litre plastic box. Standard chest drain tubing (R54502) has been used to connect the chest drain bottle to a medical air cylinder. (B) The assembled COVID-19 anti-viral filter, comprised of a heat and moisture exchange (HME) filter (Teleflex Humid-Vent Filter Compact, 19402T), attached via a $5 \mathrm{~cm}$ section of standard chest drain tubing (Rocket Medical R54502) and the proximal adapter from a size 8 endotracheal tube (Portex 100/199/080). Detailed instructions for use are provided in the online supplemental appendix.

for the Surgery of Trauma (AAST) ${ }^{7}$ to recommend risk mitigation of some form until the level of risk involved is more clearly understood. Risk mitigation options include connection of all patients to wall suction, use of a digital chest drain system or use of a bespoke anti-viral filter attached to a standard chest drain bottle. ${ }^{6}$ The objectives of this study were to determine (a) whether a bubbling chest drain is aerosol-generating and (b) the efficacy of an anti-viral filter developed in-house. We chose this option since wall suction greatly restricts patient mobility and digital drainage systems do not contain suitable viral filters for exit gases.

\section{METHODS}

The experimental set-up used is shown in figure 1. An underwater seal chest drain bottle (R54500, Rocket Medical UK) was set up according to the manufacturer's instructions and placed inside a sealable 60-litre plastic box. The drain tubing (Ref R54502) was attached to a medical air cylinder via an airtight conduit in the wall of the box. A multichannel particle counter (TSI Aerotrak 9310 Aerosol Monitor) was placed inside the box, allowing measurement of particle count/cubic foot $\left(\mathrm{pc} / \mathrm{ft}^{3}\right)$ within six channel sizes: $0.3-0.5,0.5-1,1-3,3-5,5-10$ and $>10$ $\mu \mathrm{m}$. Stabilised particle counts at different flow rates (without and with the filter attached) were compared by Wilcoxon signed rank test (R V.4.0.2 (Vienna, Austria)); $p$ values were adjusted for multiple comparisons by the Bonferroni method. For filter comparisons, relative differences, normalised to without-filter readings, were assessed. Ethical approval was not required.

\section{Viral filter}

A COVID-19 anti-viral filter device was designed by the study team and manufactured using repurposed equipment (see figure 1, and online supplemental for detailed instructions for use). The completed assembly was comprised of a heat and moisture exchange filter normally used on a ventilator circuit (Teleflex HumidVent Filter Compact, 19402T), a $5 \mathrm{~cm}$ section of standard chest drain tubing (Rocket Medical R54502) and the proximal adapter from a size 8 endotracheal tube (Portex 100/199/080). The safe functioning of the filter was assessed within a Failure Mode and Effects Analysis framework (BS EN ISO 14971:2012: application of risk management to medical devices). This included demonstration that over 24 hours of continuous flow at $5 \mathrm{~L} /$ $\min$, the pressure within the bottle rose by no more than $0.3 \mathrm{~cm} \mathrm{H}_{2} \mathrm{O}$, suggesting the filter has minimal impact on drain function.

\section{Aerosol measurement}

Particle concentrations in the air surrounding the chest drain were initially sampled without the filter attached. Baseline conditions were first sampled for $20 \mathrm{~min}$. Medical air was then pumped through the circuit for $20 \mathrm{~min}$ at $1 \mathrm{~L} / \mathrm{min}$, before being switched off, allowing baseline conditions to re-stabilise over a further $20 \mathrm{~min}$. After each $60 \mathrm{~min}$ experiment, the box was opened, measurements were recorded and the unit resealed. The experiment was repeated using flow rates of 3 and $5 \mathrm{~L} /$ min, and then all three experiments were repeated with the filter attached (see figure 1B). Each experiment was conducted on a single occasion.

\section{RESULTS}

Particle concentrations measured in each channel at 1, 3 and $5 \mathrm{~L} / \mathrm{min}$, without the filter attached are summarised in figure 2, absolute values reported in online supplemental table 1. Particle emissions increased with increasing air flow, with the largest increase observed in the smaller particles $(0.3-3 \mu \mathrm{m})$. Concentration of the smallest particles $(0.3-0.5 \mu \mathrm{m})$ increased from background levels by 

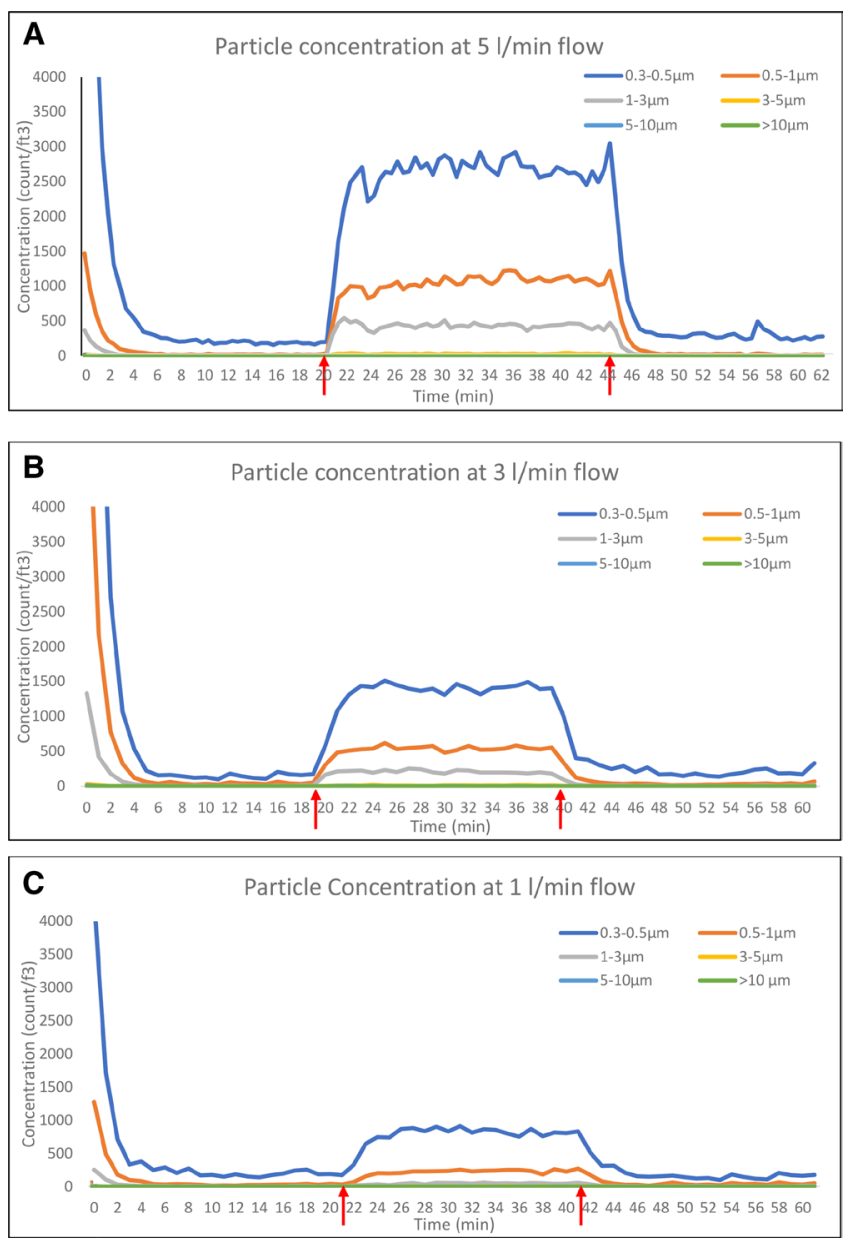

Figure 2 Particle concentrations, as measured by the TSI Aerotrak 9310 Aerosol Monitor, while air was bubbled through a standard underwater seal chest drain (Rocket R54500) without a filter at flow rates of (A) $1 \mathrm{~L} / \mathrm{min},(B) 3 \mathrm{~L}$ min and (C) $5 \mathrm{~L} / \mathrm{min}$. The red arrows on each graph show when the air flow was turned on and then turned off again.

700,1400 and $2500 \mathrm{pc} / \mathrm{ft}^{3}$ at 1,3 and $5 \mathrm{~L} / \mathrm{min}$, respectively (see figure 2$)$. Particle counts $\left(\mathrm{pc} / \mathrm{ft}^{3}\right)$ significantly increased (based on Bonferroni-adjusted $\mathrm{p}<0.00086$ ) at all flow rates and in all channel sizes, except at $1 \mathrm{~L} / \mathrm{min}$ in the $5-10 \mu \mathrm{m}$ channel (adjusted $\mathrm{p}$ value not significant at 0.02 ).

Particle concentrations measured in each channel at 1 , 3 and $5 \mathrm{~L} / \mathrm{min}$, with the filter attached are summarised in figure 3, absolute values reported in online supplemental table 1. Particle counts $\left(\mathrm{pc} / \mathrm{ft}^{3}\right)$ were notably lower in all channels compared with without-filter measurements. Counts of the smallest particles significantly reduced between baseline and initiation of air flow (based on Bonferroni-adjusted $\mathrm{p}<0.00086)$ at $1 \mathrm{~L} / \mathrm{min} \quad(0.3-0.5$ $\mu \mathrm{m}$ only), 3 and $5 \mathrm{~L} / \mathrm{min}(0.3-0.5,0.5-1,1-3 \mu \mathrm{m}$ channels), likely reflecting dilution of background aerosols by filtered air. With the filter added, normalised particle count differences were significantly lower $(\mathrm{p}<0.00086)$ in the smaller channels $(0.3-0.5,0.5-1,1-3,3-5 \mu \mathrm{m})$ at all flow rates, compared with without-filter values.
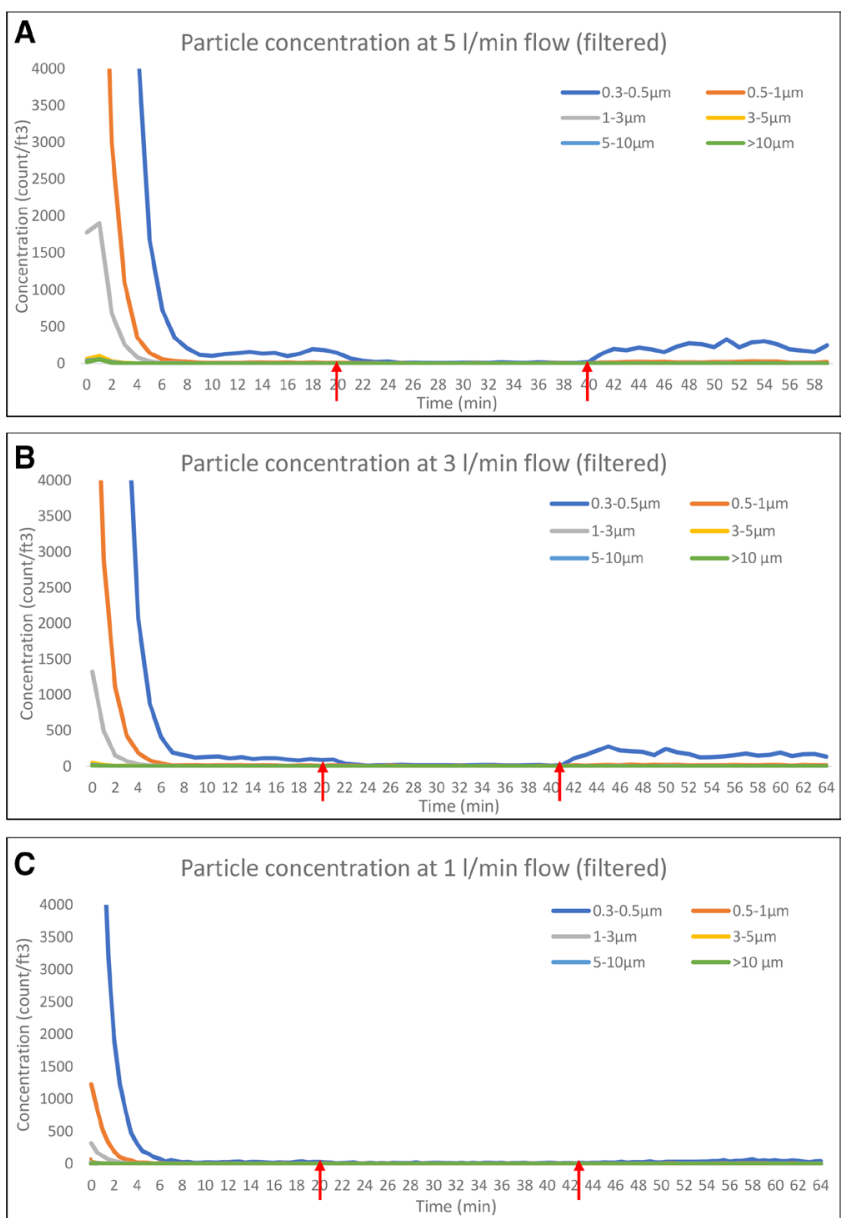

Figure 3 Particle concentrations, as measured by the TSI Aerotrak 9310 Aerosol Monitor, while air was bubbled through a standard underwater seal chest drain (Rocket R54500) with a filter at flow rates of (A) $1 \mathrm{~L} / \mathrm{min}$, (B) $3 \mathrm{~L} / \mathrm{min}$ and (C) $5 \mathrm{~L} / \mathrm{min}$. The red arrows on each graph show when the air flow was turned on and then turned off again.

\section{DISCUSSION}

The data reported here indicate that particles in the aerosol range $(<5 \mu \mathrm{m})$ are generated by a bubbling chest drain at continuous flow rates of at least $1 \mathrm{~L} / \mathrm{min}$. Aerosol emissions increased with increasing air flow, simulating a high-volume air-leak, as might be expected following thoracic surgery, in mechanically ventilated patients or patients with a large spontaneous alveolar-pleural fistula complicating bullous lung disease. These data were recorded as part of a comprehensive risk assessment process, which demonstrated no significant limitation of air flow through the chest drain circuit with the filter in situ.

Aerosols are typically generated by air moving across the surface of a liquid, with increasing air forces generating smaller particles. ${ }^{1}$ This is consistent with the observations reported here in that unfiltered emissions of the smallest particles $(0.3-0.5 \mu \mathrm{m})$ increased progressively from 1 to 3 to $5 \mathrm{~L} / \mathrm{min}$. Our findings are also concordant with a recent study reported by Akhtar et al, in which a similar anti-viral filter was evaluated and produced a qualitative 
reduction in droplet emissions. However, droplet size, and therefore aerosolisation potential were not examined. ${ }^{8}$ These data support risk mitigation in patients with suspected or proven COVID-19, as recommended by the BTS $^{6}$ and the AAST. ${ }^{7}$ However, the absolute risk involved remains uncertain and the experimental set-up used cannot be considered exactly equivalent to a bubbling drain in a clinical setting. Pleural effusion and pneumothorax appear uncommon complications of COVID-19 (occurring in $\sim 5 \%$ and $\sim 1 \%$ of cases, respectively ${ }^{6}$ ) and an aerosol-generating chest drain can clearly only be an infection risk if SARS-CoV-2 is (a) present in any effusion drained (which may be of minimal volume in patients with pneumothorax and major air-leaks) and (b) remains viable long enough to be aerosolised. Lescure $e t a \hat{l}^{3}$ and Mei $e t a l^{t}$ have recently reported cases of SARS-CoV-2 positive effusions, but in these cases air-leak was not reported as a significant component, and larger studies are needed to define the prevalence and risks of unfiltered air-leaks in COVID-19 more clearly. In a recent postmortem series, Schaller et al reported that $50 \%$ of patients with fatal COVID-19 had associated pleural effusion, of which $50 \%$ were PCR positive. ${ }^{9}$ The risk of nosocomial transmission via an unfiltered air-leak may therefore be highest in patients with the most advanced disease in the event of a secondary pneumothorax complicating positive pressure ventilation. With regard to viability over time, SARS-CoV-2 has been shown to remain viable in aerosols for several hours and on surfaces for several days, ${ }^{10}$ so could probably persist in a chest drain bottle for sufficiently long to be an infection risk.

The experiments reported here were carried out in a controlled environment with minimal background environmental disturbances. It is therefore unknown how normal background activities (eg, staff proximity, the opening and closing of doors), which can affect the rate of aerosols resuspension on surfaces, would affect concentrations in a clinical setting. Given that our data were recorded at flow rates of 1,3 and $5 \mathrm{~L} / \mathrm{min}$, it should also be acknowledged that the particle emission profile of smaller volume air-leaks cannot be directly concluded from our data. Nevertheless, it appears clear that a bubbling chest drain is a potential source of aerosolised particles, and that dispersion can be prevented using a simple anti-viral filter. These data should be considered when designing measures to reduce in-hospital spread of SARS-CoV-2.

Contributors CD had full access to all of the data in the study, contributed substantially to the study design, data analysis and interpretation, and wrote a first draft of part of the manuscript. AK contributed substantially to the study design and interpretation, and wrote a first draft of part of the manuscript. SF and RS had full access to all of the data in the study, contributed substantially to the study design, data analysis and interpretation, and the writing of the manuscript. ST, KF,
JF, LM, KGR, CM contributed substantially to the study design, data analysis and interpretation, and the writing of the manuscript. KGB conceived the study, had access to the data and takes responsibility for the integrity and the accuracy of the data analysis, had the primary role in writing and submitting the manuscript and acts as guarantor.

Funding The authors have not declared a specific grant for this research from any funding agency in the public, commercial or not-for-profit sectors.

Competing interests KGB has received research funding from Rocket Medical UK for other studies.

Patient consent for publication Not required.

Provenance and peer review Not commissioned; externally peer reviewed.

Data availability statement Data are available upon reasonable request. Requests should be made to the Corresponding Author.

Supplemental material This content has been supplied by the author(s). It has not been vetted by BMJ Publishing Group Limited (BMJ) and may not have been peer-reviewed. Any opinions or recommendations discussed are solely those of the author(s) and are not endorsed by BMJ. BMJ disclaims all liability and responsibility arising from any reliance placed on the content. Where the content includes any translated material, BMJ does not warrant the accuracy and reliability of the translations (including but not limited to local regulations, clinical guidelines, terminology, drug names and drug dosages), and is not responsible for any error and/or omissions arising from translation and adaptation or otherwise.

Open access This is an open access article distributed in accordance with the Creative Commons Attribution Non Commercial (CC BY-NC 4.0) license, which permits others to distribute, remix, adapt, build upon this work non-commercially, and license their derivative works on different terms, provided the original work is properly cited, appropriate credit is given, any changes made indicated, and the use is non-commercial. See: http://creativecommons.org/licenses/by-nc/4.0/.

ORCID ID

Kevin G Blyth http://orcid.org/0000-0003-2972-6641

\section{REFERENCES}

1 WHO. Infection prevention and control of epidemic- and pandemicprone acute respiratory infections in health care, 2014. Available: https://apps.who.int/iris/bitstream/handle/10665/112656/ 9789241507134_eng.pdf;jsessionid=648503CE9E2AB916BB9E C63D245DE2E9? sequence $=1$ [Accessed 5 Jul 2020].

2 Houlihan C, Vora N, Byrne T, et al. SARS-CoV-2 virus and antibodies in front-line health care workers in an acute hospital in London: preliminary results from a longitudinal study. Medrxiv 2020.

3 Lescure F-X, Bouadma L, Nguyen D, et al. Clinical and virological data of the first cases of COVID-19 in Europe: a case series. Lancet Infect Dis 2020;20:697-706.

4 Mei F, Bonifazi M, Menzo S, et al. First detection of SARS-CoV-2 by real-time reverse transcriptase-polymerase chain reaction assay in pleural fluid. Chest 2020;158:e143-6.

5 Li Y-K, Peng S, Li L-Q, et al. Clinical and Transmission Characteristics of Covid-19 - A Retrospective Study of 25 Cases from a Single Thoracic Surgery Department. Curr Med Sci 2020;40:295-300.

6 Hallifax R, Wrightson J, Bibby A, et al. Pleural services during COVID-19 pandemic, 2020. Available: https://www.brit-thoracic.org. uk/document-library/quality-improvement/covid-19/pleural-servicesduring-covid-19-pandemic/ [Accessed 5 Jul 2020].

7 Pieracci FM, Burlew CC, Spain D, et al. Tube thoracostomy during the COVID-19 pandemic: guidance and recommendations from the AAST acute care surgery and critical care committees. Trauma Surg Acute Care Open 2020;5:e000498.

8 Akhtar MR, Ricketts W, Fotheringham T. Use of an antiviral filter attached to a pleural drain bottle to prevent aerosol contamination with SARS-CoV-2. Clin Med 2020;20:e60-1.

9 Schaller T, Hirschbühl K, Burkhardt K, et al. Postmortem examination of patients with COVID-19. JAMA 2020;323:2518.

10 van Doremalen N, Bushmaker T, Morris DH, et al. Aerosol and surface stability of SARS-CoV-2 as compared with SARS-CoV-1. N Engl J Med 2020;382:1564-7. 